\title{
SOCIAL CLASS AND PROGNOSIS IN SCHIZOPHRENIA. PART II
}

\author{
BY
}

\section{B. COOPER}

Glenside and Barrow Hospitals, Bristol

The information obtained from the first-admission series was felt to be incomplete, for several reasons. First, a number of the patients had been lost sight of after the first admission; while it could be safely assumed that none had re-entered the Bristol Mental Hospital group, it was possible that some had subsequently been admitted to other mental hospitals without the Bristol hospital being notified. (Normally a request from another mental hospital for loan of a patient's case-sheets was entered in his record, but this may not have been done in every case.) Secondly, while the criteria used as indices of prognosis are widely accepted, one would wish to have more definite information on the patient's condition at a given length of time after his discharge from hospital. Thirdly, more precise information was required about the unfavourable factors operating in the lower social classes.

\section{METHOD}

The period 1953 to 1957 inclusive was chosen, as this made possible a follow-up of at least 2 years in every case, and was the most recent sample fulfilling this condition which could be obtained. A "case" was therefore defined as: "A male patient discharged from Bristol Mental Hospital group during the period 1953-7, after his first stay in any mental hospital, and with a diagnosis of schizophrenia". The other criteria adopted were similar to those used for the admission series.

Diagnosis.-This was initially obtained from the patient's case-notes, and was the diagnosis given at the time of discharge from hospital. Any modification of diagnosis on subsequent admissions was noted, and if the patient, in the light of his later progress, was given a diagnosis other than schizophrenia, he was discarded from the series. The diagnosis was also reassessed during the course of the survey by interviews with the patient and his relatives, and by discussion with the senior psychiatrist most in touch with his case. As a result the final diagnosis was considered to be reliable in the great majority of cases included. Formal diagnoses were based on the W.H.O. International Statistical Classification (1949), but not accepted unless a convincing clinical description was recorded in the case-notes.

Social Class.-This was first obtained by comparing the patient's occupation before admission, as recorded in the case-notes, with the Registrar General's "Classification of Occupations" (General Register Office, 1951).

Later, during the follow-up investigation, the patient's occupational record was checked at an interview with him or his relatives, and his social class was amended if it had not been recorded correctly. As has been mentioned already, the information obtained from the clinical notes and social worker's reports was almost always accurate; in about a dozen cases, however, the patient's social class rating was amended after interview.

An interview schedule, covering 35 items considered relevant in assessing outcome, was completed for each patient under survey, in two stages. The first stage consisted of a study of the patient's case-notes. covering all in-patient treatment from the date of first admission, from which the following data was extracted:

(1) Age at first discharge.

(2) Marital status at first discharge.

(3) Diagnosis at first discharge.

(4) Duration of stay in hospital.

(5) Treatment received while in hospital.

(6) In-patient status before discharge.

(7) Clinical condition at discharge, and prognosis given, if any. 
(8) Occupation and social status before admission.

(9) Address to which discharged.

(10) Whether discharged to relatives or to other accommodation.

(11) Dates of any recorded subsequent admissions to hospital.

The second stage consisted of an interview with an informant who was able to give reliable information about the patient's progress and current condition. Whenever possible the informant was the housekeeper of the domestic group in which the patient was living, or had lived for the greater part of the time since his discharge from hospital. When the patient was living alone he himself was interviewed. Finally, some 35 patients who were currently receiving in-patient treatment, or were attending psychiatric clinics, were interviewed, as well as their relatives.

During the second stage of investigation, the following information was collected:

(1) Composition of the patient's current household.

(2) Current occupation and length of time for which it had been followed.

(3) Current economic status (self-supporting, partly dependent, or completely dependent).

(4) Present personality and social behaviour (normal, mildly disturbed, or grossly disturbed).

(5) Standard of self-care, judged by toilet, care of appearance, and ability to handle money and look after his affairs.

(6) Whether currently under any form of psychiatric supervision.

(7) Work record before the first admission to hospital, with particular reference to job or jobs held in the year immediately preceding admission.

(8) Details of work record during the 12 months immediately after the first discharge from hospital, with particular reference to periods of unemployment and difficulty in returning to work.

(9) Later admissions to a mental hospital after first discharge.

(10) Assessment of social class of household.

(11) Assessment of reliability of interview.

A study of the case-histories showed that a number of patients, who had been admitted to hospital initially as voluntary patients and had shortly afterwards discharged themselves against medical advice while still severely mentally disturbed, had been returned under certificate within a short time, and had then remained in hospital until their condition was relieved. It was felt that, for such cases, to take the day when the patient departed against advice as the date of first discharge, would give a misleading picture, since any attempt at rehabilitation and return to normal life was virtually impossible. For this reason the date of discharge was taken to mean "the date on which the patient was first discharged from hospital for a period of over one month". If a patient had been readmitted in less than one month, his subsequent stay in hospital was counted, for the purpose of this survey, as part of his first admission stay. For certified patients who were sent out "on trial", the date of discharge was taken to be that on which their period of "trial" was completed and they were officially discharged. This was thought to be more logical, since a patient "on trial" was not permitted to seek work.

The total number of male schizophrenics discharged during the period under survey was 237 (not counting six who went direct to other mental hospitals). Of this total, fifteen were known to have gone to addresses outside the Bristol area. During the survey, six patients were found to have died since discharge, five were rejected as not convincing cases of schizophrenia, two refused interview, and seventeen were "non-contacts", that is, they were eventually discovered to have left the Bristol area, or were simply untraceable. Eventually, therefore, a total of 192 interview schedules was completed.

\section{RESULTS}

The interview schedules being completed, the sample was analysed as before, for distribution of social class, age, and marital status (Table I).

\section{TABLE I}

AGE, MARITAL STATUS, AND SOCIAL CLASS OF DISCHARGE SERIES

\begin{tabular}{l|l|l|c|c|c|c}
\hline \multicolumn{1}{|l|}{ Social Class ... } &.. & I and II & III & IV and V & Total \\
\hline \multirow{3}{*}{ No. of Cases } & Single &.. & 13 & 66 & 47 & 126 \\
\cline { 2 - 7 } & Ever Married & 7 & 42 & 17 & 66 \\
\cline { 2 - 7 } & Total & 20 & 108 & 64 & 192 \\
\hline
\end{tabular}

The distribution by social class is approximately the same as that found in the admission series, the main difference being a slightly higher proportion of Class III patients. (The proportion of Class IV and $\mathrm{V}$ cases, nineteen and 45 respectively, was also roughly as expected.)

Also as in the admission series, there is no positive relation between marital status and social class $\left(\chi^{2}=2 \cdot 718 ; d . f .=2 ; p>0.05\right)$, and there is no class gradient for age at discharge. Neither of these 
factors, therefore, can be responsible for differences of outcome. Other factors of prognostic significance which must be considered, include duration of hospital stay, treatment given in hospital, and condition at discharge.

Duration of stay in hospital has already been discussed, and the bad prognosis of the long-stay patient has been indicated. Whether this holds good for the long-stay patient who is eventually discharged from hospital is not so clear. Brown, Carstairs, and Topping (1958), studying long-stay patients only, found that therewas no direct relationship between length of stay and success or failure after discharge, but the schizophrenic patients with over 10 years' stay actually did better than the rest. It seems unlikely, however, tha tsuch a relationship would be found if short-stay patients only were considered. One would expect rather that, of patients discharged with medical approval, the prognosis would be better for the milder short-stay cases.

Table II shows the mean duration of stay, together with the number of long-stay patients in each social class. The total number of patients leaving after 2 years or more is small, as might be expected, considering the relatively poor chance of discharge for such patients. Accordingly, to give a clearer picture, the number of patients leaving after one year or more has also been included. There is a tendency for those in the lower social classes to have a longer duration of stay and a higher proportion of long-stay patients; these points suggest that these patients may have a less favourable outcome in the years after discharge. The number of chronic patients at this stage is small, however, and these patients were not faced with the more severe problem of rehabilitation of the chronic patient.

TABLE II

DURATION OF HOSPITAL STAY, BY SOCIAL CLASS

\begin{tabular}{c|c|c|c|c}
\hline \multirow{2}{*}{ Hospital Stay } & \multicolumn{3}{|c|}{ Social Class } \\
\cline { 2 - 5 } & I and II & III & IV and V & Total \\
\hline Mean Duration (mths) & $4 \cdot 8$ & $6 \cdot 3$ & $8 \cdot 3$ & $6 \cdot 8$ \\
\hline $\begin{array}{l}\text { Patients Leaving after } \\
\text { 2 Years or More }\end{array}$ & 1 & 5 & 3 & 9 \\
\hline $\begin{array}{l}\text { Patients Leaving after } \\
\text { 1 Year or More }\end{array}$ & 1 & 10 & 11 & 22 \\
\hline
\end{tabular}

No significant relationship was found between the treatment used and the social class distribution, though there was a discernible trend for the lower social classes to have a higher proportion of cases given no systematic treatment. Similarly, when the condition at discharge was considered, there was no significant excess of "Not Improved" patients in Classes IV and V, although the number in this category was in excess of the expected frequency.

To recapitulate, while patients in lower social classes have on average been longer in hospital and show a tendency towards a less satisfactory clinical condition at discharge, neither of these factors is sufficiently marked to be regarded as of major importance in determining the later outcome.

MEASURement of Outcome.-Three inain points were considered: the success or failure of rehabilitation, the readmission rate, and the total time spent in hospital in the ensuing 2 years.

(a) Success or Failure of Rehabilitation. - The success or failure of the patient's first year after discharge is of considerable importance to the long-term prognosis. It is during this time that he attempts, with the aid of medical and social supervision, to return to normal life in the community and to gainful employment. If he is successful he will be fortified against the onset of further attacks; his own self-confidence, and the confidence of others in him, will be restored, and he will be accepted once more as a normal person. On the other hand, failure to make a readjustment will discourage the patient, engender a pessimistic attitude towards his future, and confirm those about him in the belief that he is irretrievably damaged. Of all patients who relapse the highest percentage do so in the first year.

In the present study, "success" was defined as "successful return to gainful employment as shown by being in work for at least 6 of the first 12 months after discharge". All patients who did not fulfil this criterion were classed as "failures", together with those who were readmitted to a mental hospital for a total of more than one month during the 12 months after discharge. These criteria were found to be closely correlated with social class (Table III).

TABLE III

SUCCESS OR FAILURE OF REHABILITATION, BY SOCIAL CLASS

\begin{tabular}{|c|c|c|c|c|c|c|}
\hline \multirow{2}{*}{\multicolumn{3}{|c|}{ Rehabilitation }} & \multicolumn{4}{|c|}{ Social Class } \\
\hline & & & \multirow{2}{*}{$\frac{I \text { and II }}{16}$} & \multirow{2}{*}{$\frac{\text { III }}{80}$} & \multirow{2}{*}{$\frac{\text { IV and V }}{33}$} & \multirow{2}{*}{$\frac{\text { Total }}{129}$} \\
\hline Success & $\ldots$ & $\ldots$ & & & & \\
\hline Failure & $\ldots$ & $\ldots$ & 4 & 28 & 31 & 63 \\
\hline
\end{tabular}


This finding is important and merits further analysis. From the criteria employed it might be due entirely to a larger number of readmissions among the lower social classes. This is not so, however; if we consider only those patients who were not readmitted in the first year, the "failure" rate is still related to social status (Table IV).

\section{TABLE IV}

SUCCESS OR FAILURE OF PATIENTS NOT READMITTED IN FIRST YEAR AFTER DISCHARGE, BY SOCIAL CLASS

\begin{tabular}{lll|c|c|c|c}
\hline \multirow{2}{*}{ Rehabilitation } & & \multicolumn{4}{c}{ Social Class } \\
\cline { 3 - 7 } & & I and II & III & IV and V & Total \\
\hline Success &.. &.. & 16 & 77 & 32 & 125 \\
\hline Failure &.. &.. & 2 & 9 & 13 & 24 \\
\hline
\end{tabular}

$\chi^{2}=7.99 ;$ d.f. $=1 ; p<0.01$

The professional man or skilled worker usually has less difficulty in returning to employment. He tends to hold the same job for a long time; usually he is paying into a superannuation fund, and he stands to gain by retaining his position. When he falls ill his place may be kept for him, if necessary for several months. Alternatively, if he has to seek a new post, his skill and qualifications may make this relatively easy.

The unskilled man, however, usually has no such advantages. He is expendable, and can be paid off on the spot. Generally speaking, the work he has been doing can be done by any other able-bodied man in search of work. When he emerges from hospital, he has less chance of being taken back by the same firm, and no qualifications to recommend him to a prospective new employer. He must have the perseverance to attend the local Labour Exchange and to travel to any place where he is told that work is available. He may find that he can live his restricted life as well on unemployment benefit and "National Assistance", as by doing the poorly-paid, possibly unpleasant, work which is all he can obtain. Thus, while patients in upper and middle social classes tend to return to their former occupations, those of lower status tend to move into a new trade, or to drift into chronic unemployment.

To test this hypothesis, all patients in the series were placed in one of three categories:

(1) Those who returned after discharge to the occupation they had held before admission. (This did not necessarily mean with the same employer, but to the same classified occupation.) Unskilled labourers who returned to the same trade were included in this category (e.g. building, the docks, catering, etc.).

(2) Those who returned to a different occupation, or for unskilled men to a different trade.

(3) Those who failed to return to gainful employment within 12 months of discharge. A patient was not classed as having returned to gainful occupation unless he had been continuously in work for 3 months or more.

These three categories are compared with the social class distribution in Table $\mathrm{V}$, which shows a positive correlation between social class and return to employment, so confirming the hypothesis stated.

TABLE V

DISCHARGED PATIENTS' RETURN TO EMPLOYMENT, BY SOCIAL CLASS

\begin{tabular}{|c|c|c|c|c|c|c|}
\hline \multirow{2}{*}{\multicolumn{3}{|c|}{ Occupation }} & \multicolumn{4}{|c|}{ Social Class } \\
\hline & & & \multirow{2}{*}{$\frac{I \text { and II }}{14}$} & \multirow{2}{*}{$\frac{\text { III }}{62}$} & \multirow{2}{*}{$\frac{\text { IV and V }}{22}$} & \multirow{2}{*}{$\begin{array}{c}\text { Total } \\
98\end{array}$} \\
\hline Same .. & .. & . & & & & \\
\hline Different & .. & .. & 2 & 30 & 17 & 49 \\
\hline \multicolumn{3}{|c|}{ No Gainful Occupation } & 4 & 16 & 25 & 45 \\
\hline
\end{tabular}

It may be said, therefore, that the schizophrenic patient's prognosis, so far as resettlement is concerned, is closely linked to his social class.

(b) Readmission Rate. - The question of readmission in the first year after discharge has been mentioned already, in discussing the criteria for "success" and "failure". Patients who "failed" were not, however, identical with those readmitted, and the latter are now considered separately. Since the follow-up survey covered a minimum period of 2 years for every patient, the readmission rate was established for both the first year and the first 2 years after discharge (Table VI, opposite). The total time spent in a mental hospital by each patient during the 2 years was also calculated, and from this the mean total length of stay could be obtained for each social class (Table VI). The readmission rate in both the first 12 months and the whole 2 years, shows a tendency to increase steadily throughout the social class gradient. The percentage of readmissions is below average for Classes I to III and above average for Classes IV and $\mathbf{V}$ for both periods. When these differences are evaluated by use of contingency tables, no significant correlation is found. (For the first year, $\chi^{2}=3.997$; d.f. $=2 ; p>0.05$, and for the 2-year period, $\chi^{2}=$ $2 \cdot 871 ; d . f .=2 ; p>0 \cdot 05$.) 
TABLE VI

READMISSION RATE AND TOTAL TIME SPENT IN HOSPITAL, BY SOCIAL CLASS

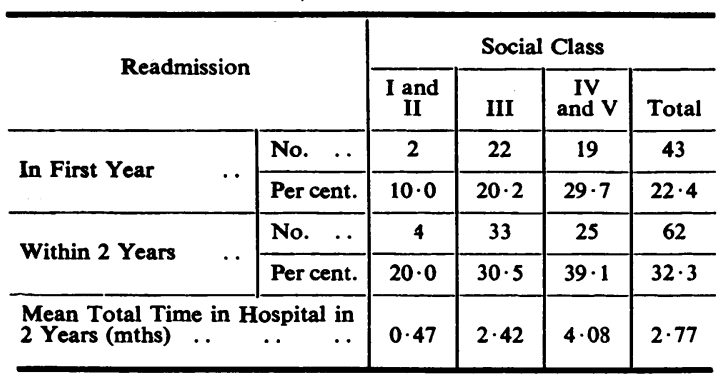

(c) Time Spent in Hospital.-When the mean total stay in hospital is considered, a much bigger disparity between the social classes can be observed. Not only has the lower group an above-average time, and the other groups below-average times, but the mean total time for Classes IV and V is approximately nine times greater than that for Classes I and II.

The amount of time spent in hospital is an important prognostic index. Harris, Linker, Norris, and Shepherd (1956) found that the total duration of stay in hospital for their group of schizophrenic patients was closely correlated with the patients' condition at follow-up (after 5 years), and they concluded that statistical studies, in which prognosis is assessed by duration of stay, give a reliable assessment of outcome. If this is so, it is one more reason to suppose that prognosis is directly related to social class. That the time spent in hospital during the first 2 years is a significant pointer to subsequent progress, can be confirmed by considering the group of patients discharged in 1953 and 1954 for whom the follow-up period extended over at least 4 years.

The distribution of the 67 cases in this group are shown in Table VII, where the disparity between the classes is even more marked than in Table VI, the mean time for Classes IV and V being approximately fifteen times greater than that for Classes I and II.

TABLE VII

TIME SPENT IN HOSPITAL IN 4 YEARS FROM DISCHARGE, BY SOCIAL CLASS

\begin{tabular}{|c|c|c|c|c|}
\hline Social Class .. & I and II & III & IV and V & Total \\
\hline Number of Cases & 10 & 36 & 21 & 67 \\
\hline $\begin{array}{l}\text { Mean Total Time in } \\
\text { Hospital in } 4 \\
\text { (mths) } \ldots\end{array}$ & 0.64 & $4 \cdot 70$ & $9 \cdot 65$ & $5 \cdot 2$ \\
\hline
\end{tabular}

It seems likely that the worse outcome for the lower class patient becomes increasingly marked as time goes on. The number of admissions to hospital of such patients is not greater, but individual admissions lead to longer stays in hospital; the upper class patients tend to have several comparatively short spells in hospital, but the lower class patients tend to stay in hospital longer, and may become chronic institutional cases after the second or third admission. As we have seen already, the low status patient runs a greater risk than the more privileged patient of becoming a chronic case even during his first admission, and this points to the fact that his prognosis is consistently less favourable from the first admission onward.

Condition at Follow-UP.- - The next step was to examine the patient's current social, economic, and psychiatric condition at the time of the follow-up survey, and to see whether this was related to social class. To do this, three ratings were made, and these were first analysed separately, and were then combined to give a general assessment of his social adjustment.

(1) Economic Status.-The patient was placed in one of three categories (Table VIII):

(a) Supporting himself entirely, and possibly others of the household as well, during the greater part of the previous 12 months.

(b) Working intermittently or part-time, but to some extent dependent financially upon his relatives, or on some form of assistance such as National Health Insurance, unemployment benefit, or National Assistance grant.

(c) Unemployed and completely dependent financially on relatives or public money. This included patients currently in a mental hospital.

\section{TABLE VIII}

ECONOMIC STATUS AT FOLLOW-UP, BY SOCIAL CLASS

\begin{tabular}{|c|c|c|c|c|c|}
\hline \multirow{2}{*}{\multicolumn{2}{|c|}{ Economic Status }} & \multicolumn{4}{|c|}{ Social Class } \\
\hline & & \multirow{2}{*}{$\begin{array}{c}\text { I and } \\
\text { II } \\
16\end{array}$} & \multirow{2}{*}{$\begin{array}{c}\text { III } \\
76\end{array}$} & \multirow{2}{*}{$\begin{array}{c}\begin{array}{c}\text { IV } \\
\text { and } V\end{array} \\
28\end{array}$} & \multirow{2}{*}{$\frac{\text { Total }}{120}$} \\
\hline Colc ounto & No. .. & & & & \\
\hline Sell-supporting & Per cent. & $80 \cdot 0$ & $70 \cdot 4$ & $43 \cdot 7$ & $62 \cdot 5$ \\
\hline \multirow{2}{*}{ Partly Dependent .. } & No... & 0 & 5 & 2 & 7 \\
\hline & Per cent. & 0.0 & $4 \cdot 6$ & $3 \cdot 2$ & 3.6 \\
\hline \multirow{2}{*}{$\begin{array}{l}\text { Completely Depend- } \\
\text { ent } \ldots\end{array}$} & No. $\ldots$ & 4 & 27 & 34 & 65 \\
\hline & Per cent. & $20 \cdot 0$ & 25 & $53 \cdot 1$ & $33 \cdot 9$ \\
\hline
\end{tabular}


Information was obtained at interview and the appropriate category was marked on the interview schedule. The patient was also given a rating of 2 , 1 , or 0 , corresponding to the three categories. The number of "partly dependent" persons being small, they were included with the "completely dependent", in constructing a contingency table. This showed a highly significant correlation $\left(\chi^{2}=15 \cdot 283 ; d . f .=2\right.$; $p<0.01$ ). In other words, at a given point from 2 to 7 years after first discharge, over one half of the lower status patients were completely dependent, as compared with not more than one quarter of other patients.

(2) Social Liability.-An assessment was made of the patient's behaviour and attitudes, and the amount of inconvenience or hardship caused to others. This assessment was based partly on the patient's own statements and the general impression gained from talking to him, but more on the evidence of his relatives or other members of the household. For patients currently in hospital at the time of the survey, the assessment was based on the medical notes and the reports of the nursing staff caring for him. Three categories were employed (Table IX):

(a) Behaving normally, restored to pre-morbid personality, or at worst displaying only mild residual personality changes.

(b) Suffering from persistent or recurring psychotic symptoms, but not grossly disturbed in behaviour, and able to maintain interpersonal relationships to a reasonable degree.

(c) Showing gross behaviour disturbances because of persistent or recurring psychotic symptoms, and unable to maintain interpersonal relationships.

TABLE IX

SOCIAL LIABILITY AT FOLLOW-UP, BY SOCIAL CLASS

\begin{tabular}{|c|c|c|c|c|c|}
\hline \multirow{2}{*}{\multicolumn{2}{|c|}{ Liability }} & \multicolumn{4}{|c|}{ Social Class } \\
\hline & & \multirow{2}{*}{$\begin{array}{c}\begin{array}{c}\text { I and } \\
\text { II }\end{array} \\
10\end{array}$} & \multirow{2}{*}{$\begin{array}{l}\text { III } \\
52\end{array}$} & \multirow{2}{*}{$\frac{\begin{array}{c}\text { IV } \\
\text { and } V\end{array}}{20}$} & \multirow{2}{*}{$\frac{\text { Tota }}{82}$} \\
\hline Normal Personality, & No. .. & & & & \\
\hline only $\quad . . \quad \ldots$ & Per cent. & $50 \cdot 0$ & $48 \cdot 1$ & $31 \cdot 2$ & $42 \cdot 8$ \\
\hline \multirow{2}{*}{$\begin{array}{l}\text { Persisting Symptoms } \\
\text { Without Gross Dis- } \\
\text { turbance } \\
\text {.. }\end{array}$} & No. $\ldots$ & 8 & 47 & 29 & 84 \\
\hline & Per cent. & $40 \cdot 0$ & $43 \cdot 5$ & $45 \cdot 4$ & $43 \cdot 8$ \\
\hline \multirow{2}{*}{$\begin{array}{l}\text { Grossly Disturbed } \\
\text { Behaviour and Re- } \\
\text { lationships .. }\end{array}$} & No. & 2 & 9 & 15 & 26 \\
\hline & Per cent. & $10 \cdot 0$ & $8 \cdot 4$ & $23 \cdot 4$ & $13 \cdot 4$ \\
\hline
\end{tabular}

The patient was given a rating of 2,1 , or 0 corresponding to the three categories. No formal list was made of the symptoms or behaviour to be included in these categories, but a subjective judgment was made for each individual. In practice, physical violence, destructiveness, impulsive outbursts, attacks of shouting and cursing, accusations directed at others, suicidal threats or attempts, and sexual misdemeanours, were placed in category $(c)$, and hallucinosis and paranoid delusions not resulting in disturbed conduct, together with suspiciousness, solitary habits, loss of outside interests, and minor eccentricities, were included in category $(b)$. Table IX shows that over half the patients continued to show a moderate or severe mental abnormality. The proportion is in excess of the expected in Social Class IV and $V$, and less than expected in the other classes. If categories $(b)$ and $(c)$ are combined to form a contingency table, the correlation is significantly positive $\left(\chi^{2}=6 \cdot 18 ;\right.$ d.f. $\left.=2 ; p<0 \cdot 05\right)$.

The lower economic status of the lower class patients is therefore to some extent related to their mental condition, and it may be that the patient who has made a good clinical recovery stands a good chance of re-establishing himself, whatever his social level. But it seems most likely that clinical condition and economic status are mutually related and interacting, and that the patient who fails to return to useful work is more prone to schizophrenic relapses. Moreover, the figures suggest that a mentally disturbed patient in the lower classes is much less likely to be able to earn his living, than a middle or upper class patient. Thus, in the Classes I and II, 30 per cent. of self-supporting patients were mentally disturbed; in Class III 22.3 per cent., and in Classes IV and V only 12.5 per cent. This points to the fact that, contrary to a commonly-held belief, schizophrenia is more disabling for those in unskilled occupations.

(3) Self-Care.-This was rated separately from "social liability" because it was thought that the two might not be closely related. A well-preserved paranoid individual might be eminently capable of looking after himself, yet cause serious social disturbance; while a chronic schizophrenic of the simple type might need a good deal of supervision, yet still be accepted by his family as docile and harmless.

Three categories were employed (Table X, opposite):

(a) A fairly normal standard of self-care, needing no help or direction as regards personal appearance, dress, toilet, and use of money.

(b) Slovenly, apathetic, or withdrawn, requiring some supervision and occasional help with appearance, toilet, or use of money. 
TABLE X

STANDARD OF SELF-CARE, BY SOCIAL CLASS

\begin{tabular}{l|c|c|c|c}
\hline \multirow{2}{*}{ Self-Care } & \multicolumn{4}{|c|}{ Social Class } \\
\cline { 2 - 5 } & I and II & III & IV and V & Total \\
\hline $\begin{array}{l}\text { No Supervision of Ap- } \\
\text { pearance, Toilet, or } \\
\text { Use of Money }\end{array}$ & 15 & 94 & 39 & 148 \\
\hline $\begin{array}{l}\text { Some Supervision of } \\
\text { Appearance, Toilet, or } \\
\text { Use of Money }\end{array}$ & 4 & 12 & 22 & 38 \\
\hline $\begin{array}{l}\text { Considerable Help with } \\
\text { Dress, Toilet, or Use of } \\
\text { Money }\end{array}$ & 1 & 2 & 3 & 6 \\
\hline
\end{tabular}

$x^{2}=14.618 ;$ d.f. $=2 ; p<0.01$

(c) Incapable of self-care through persistent mental illness, and needing considerable help with dress, toilet, and the handling of money.

Each patient was rated 2,1 , or 0 , according to the degree of self-care displayed.

Table $\mathrm{X}$ shows that the standard of self-care is directly related to the social class gradient.

It is interesting to note how few of the patients studied, including those currently in mental hospital, needed considerable help in self-care and management; this is a reflection of the changing pattern both of schizophrenia and of the mental hospital chronic wards.

(4) Social Adjustment.-The ratings obtained for economic status, social liability, and self-care were combined to give a total "Social Adjustment" score (Table XI). This varied from a possible maximum of six points to a possible minimum of no points. Patients with five or six points were classed as having a "good" level; patients with three or four points as having a "fair" level; and patients with one, two, or no points as having a "poor" level. There is a significant correlation between level of social adjustment and the social class gradient $\left(\chi^{2}=16 \cdot 29 ;\right.$ d.f. $=2$; $p<0.01$ ).

\section{TABLE XI}

LEVEL OF SOCIAL ADJUSTMENT, BY SOCIAL CLASS

\begin{tabular}{|c|c|c|c|c|c|c|}
\hline \multirow{2}{*}{\multicolumn{3}{|c|}{$\begin{array}{c}\text { Level of } \\
\text { Social } \\
\text { Adjustment }\end{array}$}} & \multicolumn{4}{|c|}{ Social Class } \\
\hline & & & \multirow{2}{*}{$\frac{I \text { and } I I}{14}$} & \multirow{2}{*}{$\frac{\text { III }}{70}$} & \multirow{2}{*}{$\frac{\text { IV and V }}{28}$} & \multirow{2}{*}{$\begin{array}{c}\text { Total } \\
112\end{array}$} \\
\hline Good & .. & . & & & & \\
\hline Fair & $\ldots$ & $\ldots$ & 3 & 25 & 12 & 40 \\
\hline Poor & .. & .. & 3 & 13 & 24 & 40 \\
\hline
\end{tabular}

These findings seem to confirm the hypothesis that the outcome of schizophrenic illness at the end of a given follow-up period will be worse for those of lower social status, and that this is related to earlier prognostic indices, such as the length of time spent in hospital and the degree of success in returning to employment following discharge.

How do these results conform with the ecological theories of schizophrenia already discussed ? We have seen that, so far as formal treatment methods are concerned, there was no great variation with social status; nor did the frequency of psychiatric follow-up vary with social class (this is also true for the present series). Whatever is responsible for the worse plight of the lower status patients, it does not appear to be primarily a difference in medical treatment. The chief reason for this is probably that only a small proportion of patients in any class were currently receiving psychiatric supervision (which was taken to include attendance at the follow-up clinics, the general hospital out-patient clinics, and the two day-hospital units available). Of a total of 110 cases found to have persisting moderate or severe disturbance of behaviour and personality, 31 were in hospital, and only 29 under out-patient supervision.

The hypothesis of schizophrenic "drift" and "downward social mobility" can now be re-examined. The first postulates that the high incidence of schizophrenia in certain areas is due to a migration of pre-schizophrenic individuals into those areas; the second that the high incidence of schizophrenia in the lower social classes is due to a downward occupational drift of the pre-schizophrenic individual. If these processes occur, it seems improbable that they will be halted after a first admission to hospital. Schizophrenia is a chronic or recurrent illness in most cases, and this is certainly true for the present series as a whole; as has been seen, nearly 60 per cent. of cases still showed clear evidence of abnormality at the time of follow-up. One might therefore expect those who at first admission still maintained their original place in the class-structure, to have drifted downwards subsequently, and to have done as badly in the long run as those already in a low class at the onset of frank psychosis. So far, however, the results tend to show that the upper class patients maintain their superiority, and in general carry a better prognosis. In an attempt to gain more evidence on this point, an examination was made of the "occupational deterioration" of the patients followed-up in this study. This was done by comparing each patient's social class before his first admission to hospital, with his current social class at the time of the survey, as based on his present occupation (Table XII). In addition to the Registrar General's five social 
classes, a sixth class, "Not Gainfully Occupied", was distinguished; this included patients currently in a mental hospital, or completely dependent financially on their family or on the community. The percentages shown in brackets include the proportion of patients in each social class who retained the same status throughout the period of follow-up.

\section{TABLE XII}

COMPARISON OF SOCIAL CLASS BEFORE FIRST ADMISSION AND AT FOLLOW-UP

\begin{tabular}{|c|c|c|c|c|}
\hline \multirow{2}{*}{$\begin{array}{l}\text { Social Class } \\
\text { at Follow-up }\end{array}$} & \multicolumn{4}{|c|}{ Social Class before First Admission } \\
\hline & I and II & III & IV & V \\
\hline I and II & $\begin{array}{c}15 \\
(75 \cdot 0 \\
\text { per cent. })\end{array}$ & 1 & - & - \\
\hline III & 1 & $\begin{array}{c}62 \\
(57 \cdot 4 \\
\text { per cent.) }\end{array}$ & 2 & - \\
\hline IV & - & 9 & $\begin{array}{c}5 \\
(26 \cdot 3 \\
\text { per cent. })\end{array}$ & 1 \\
\hline $\mathbf{V}$ & 一 & 9 & 5 & $\begin{array}{c}17 \\
(37 \cdot 8 \\
\text { per cent. })\end{array}$ \\
\hline $\begin{array}{l}\text { Not Gainfully } \\
\text { Occupied }\end{array}$ & 4 & 27 & 7 & 27 \\
\hline
\end{tabular}

From Table XII a number of inferences may be drawn. To begin with, there is a degree of "downward social mobility" in the patient sample; 89 patients have dropped to a lower social class, and 65 of these are classed as "not gainfully occupied", while the remaining 24 are doing a less skillful type of work than before their illness.

Secondly, there is very little "upward social mobility"; only four patients showed an improvement in social status, each having moved up one class. This does not correspond to the idea of schizophrenics as "achievers" and "over-achievers", although it does not preclude an initial rise in social class before the onset of the psychosis, which has been followed by a subsequent fall.

Thirdly, the majority of patients who drop from the original social class become "not gainfully occupied"; in other words, if a patient is too ill to maintain his previous level, he will probably not be able to work at all. Comparatively few had made a satisfactory adjustment in a less skilled occupation. Thus, of the original members of Classes I and II, one had dropped to social class III, and four were "not gainfully occupied".
Fourthly, the higher the patient's original social status, the better his chances of maintaining it. The Class IV and V patients were much the most vulnerable in this respect, and of the Class $\mathrm{V}$ cases in particular, over half had become "not gainfully occupied".

While there is, therefore, a certain degree of "downward social mobility" among these patients, it does not seem to be the most important factor in the observed social class gradient of schizophrenia. The only satisfactory explanation for the consistently worse outcome of the lower class patients is that contained in the third ecological hypothesis, namely, that they are subjected to some form of increased socio-economic stress: if this explains the differential outcome of the illness, it seems probable that it also does much to determine its incidence.

TYPE OF Living-Group.-In the analysis of the admission series, the role of "Social Isolation" was discussed, and it was suggested that, while this was rather an over-simplification of a vague concept, the patient's having been in or out of his family setting gave a practical criterion of isolation. Whether the same factor of social isolation continues to play an unfavourable part in the schizophrenic's subsequent progress is undetermined. Brown and others (1958) found some evidence to suggest that the long-stay schizophrenics who went out of hospital to lodgings, or to other kin, did better than those who went to wives or to hospitals, while the patients who went to their parents did worst of all. These authors suggest that this fact may be related to the wellrecognized phenomenon of the over-protective mother of the schizophrenic. If this is so, it would appear to be somewhat opposed to the "social isolation" hypothesis. On the other hand, Mettler, Crandell, Wittenborn, Litten, Feiring, and Carpenter (1954), in trying to assess the prognosis of schizophrenic patients who were candidates for psychosurgery, found that extramural environmental factors after discharge were of very little significance, except for a small number of the less favourable cases, who seemed to do better with extra-familial placement.

To check the effect on the present series, if any, of the type of living group to which patients were discharged, this was compared with two of the criteria of outcome already described: readmission to a mental hospital during the follow-up period, and economic status at the time of the survey. Four types of living group were distinguished: parental home, marital home, residence with any relatives other than parents or wife, and residence alone or 
in lodgings (none of the patients in this survey were discharged to any kind of after-care hostel or longstay annexe). The results for the two criteria of outcome are shown in Table XIII, where "in work" is taken to mean in full-time employment for over half of the previous 12 months.

TABLE XIII

OUTCOME ASSESSED BY TYPE OF LIVING GROUP

\begin{tabular}{|c|c|c|c|c|c|c|}
\hline \multirow{2}{*}{\multicolumn{2}{|c|}{$\begin{array}{l}\text { Result at } \\
\text { Follow-up }\end{array}$}} & \multicolumn{5}{|c|}{ Type of Living Group } \\
\hline & & \multirow{2}{*}{$\begin{array}{c}\text { Parents } \\
38\end{array}$} & \multirow{2}{*}{$\frac{\text { Spouse }}{13}$} & \multirow{2}{*}{$\begin{array}{c}\begin{array}{c}\text { Other } \\
\text { Kin }\end{array} \\
6\end{array}$} & \multirow{2}{*}{\begin{tabular}{|c|}
$\begin{array}{c}\text { Alone } \\
\text { or in } \\
\text { Lodgings }\end{array}$ \\
5
\end{tabular}} & \multirow{2}{*}{\begin{tabular}{|r} 
Tota \\
62
\end{tabular}} \\
\hline Readmitted & No. .. & & & & & \\
\hline 2 Years & Per cent. & $36 \cdot 9$ & $23 \cdot 2$ & $30 \cdot 0$ & $38 \cdot 5$ & \\
\hline \multirow{2}{*}{$\begin{array}{c}\text { Not } \\
\text { Readmitted }\end{array}$} & No. ... & 65 & 43 & 14 & 8 & \multirow{2}{*}{130} \\
\hline & Per cent. & $63 \cdot 1$ & $76 \cdot 8$ & $70 \cdot 0$ & $61 \cdot 5$ & \\
\hline \multirow{2}{*}{ In Work } & No.. & 57 & 45 & 13 & 5 & \multirow{2}{*}{120} \\
\hline & Per cent. & $55 \cdot 3$ & $80 \cdot 4$ & $65 \cdot 0$ & $38 \cdot 5$ & \\
\hline \multirow{2}{*}{ Not in Work } & No. .. & 46 & 11 & 7 & 8 & \multirow{2}{*}{72} \\
\hline & Per cent. & $44 \cdot 7$ & $19 \cdot 6$ & $35 \cdot 0$ & $61 \cdot 5$ & \\
\hline
\end{tabular}

For both criteria the order of outcome is the same; married men returning to their wives did best; those returning to other relatives came next; patients discharged to their parents did less well, and not much better than the least successful group of all, those discharged to live alone or in lodgings.

These results, taken alone, are not meaningful, since they do not take into consideration the relative ages of the different groups, and the differences in clinical condition at discharge. Thus, patients going to their parents were younger on average than those going to their wives, and a rather higher proportion of patients who were "not improved" went to parental homes. Moreover, the total number of patients who went to lodgings is small (thirteen only, compared with the thirty patients in the admission series who were noted as "out of family setting"). This is possibly due to the fact that patients with no relatives have a comparatively poor chance of discharge. As far as they go, however, the figures are consistent with both the hypotheses already mentioned: that patients going to live alone suffer from the effects of "social isolation", and that those returning to the parental home may be unfavourably affected by parental "over-protection".
The type of living group was next compared with the patient's social class (Table XIV). The only significant feature is the preponderance of lower class patients in those living alone or in lodgings. This confirms the finding for the admission series, that lower class status and "social isolation" are positively related. Apart from this, there is a tendency for lower class patients to go to their parents rather more frequently, and for upper class patients to go to wives or "other relatives" more frequently, this being associated with a more favourable prognosis.

TABLE XIV

TYPE OF LIVING GROUP, BY SOCIAL CLASS

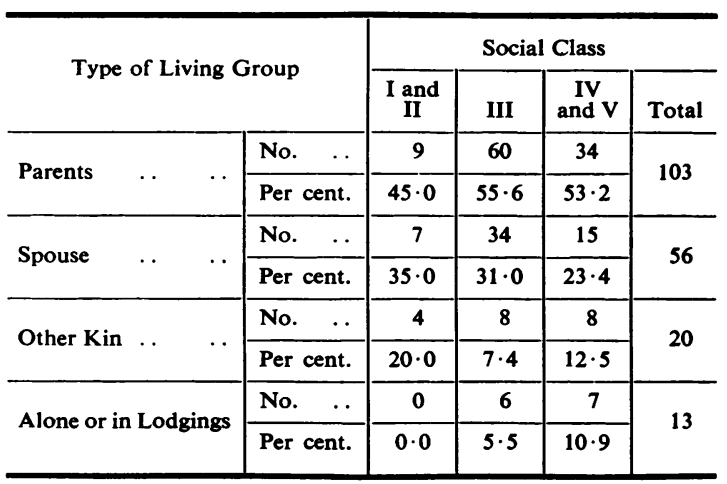

\section{CONCLUSIONS}

(1) Distribution of age at discharge, and of marital status, was not related to the social class gradient in this series of patients.

(2) There was no significant class distribution of the types of treatment which these patients had received in hospital.

(3) The length of stay in hospital before first discharge was related to social class, but the number of long-stay patients was small, and this could not be regarded as an important prognostic factor.

(4) There was a significant relation between social class and success or failure of rehabilitation in the first year after discharge.

(5) There was also a significant relation between social class and return to former occupation.

(6) Social class did not significantly affect a patient's likelihood of readmission within the follow-up period, but it did considerably affect the total amount of time spent in hospital. 
(7) The level of social adjustment at the time of follow-up, as measured by his economic status, effect on his relatives, and standard of self-care, was significantly related to social class.

(8) Psychiatric follow-up and supervision since discharge did not appear to affect the outcome.

(9) The findings favoured the hypothesis that an increased socio-economic stress is exerted on those in the lower social classes. This stress is related to, but not identical with, "social isolation".

(10) The findings suggest that schizophrenic "drift" plays a positive, but relatively minor, role in the ecology of schizophrenia, and that occupational deterioration is most severe for patients who were originally of low occupational status.

(11) While the type of living group to which the patient is discharged appears to be of some importance in prognosis, this was not related to the social class distribution of the follow-up series, except that the small group of patients living out of family setting were predominantly of lower social status.

\section{Discussion}

It has been noted that, while a large number of prognostic factors are recognized in schizophrenia, those concerned with the patient's socio-economic status have been touched on in rather general terms. They may now, however, be formulated more precisely:

Prognosis in schizophrenia is directly related to social status. Patients from the upper social classes, with high occupational prestige and good employment records, carry a good prognosis; conversely, patients from the lower social classes, with low occupational prestige and poor employment records, have a correspondingly bad prognosis. Furthermore, prognosis is related to the patient's domestic circumstances. Those who before their illness have been living in a family-group environment, and those who after treatment return to such a group, tend to have a good outcome; conversely, those who have been living out of the family-group, and those who after treatment do not return to the family-group, have a correspondingly bad outcome.

The conclusions drawn from this investigation seem to favour the hypothesis that conditions of socio-economic stress, suffered most by those in the lower social classes, are important in the genesis of schizophrenia. Comparatively little evidence was found of a downward social drift in the patients under survey; on the contrary, the findings seemed to indicate that patients who had reached a moderately high occupational level before their illness tended to remain at that level, and that it was those who had low occupational prestige who suffered the most severe disability. This confirms the findings of Hollingshead and Redlich (1958) and other investigators: it is the under-privileged, the indigenous poor, who are worst affected by this malady. That section of the community which provides the highest proportion of cases, is least able to make an adequate adjustment to the disease, once established (Adler, 1956). This does not preclude the possible significance of intergeneration social mobility. It may be that the lower class patients studied in this investigation owed their inferior status at least in part to genetic factors, or to early developmental influences, which determined their personalities, hence the pattern of their low educational attainments and subsequent poor occupational records. As has been said, the question whether such inter-generation social mobility is greater than average in the families of schizophrenics remains unsettled, and the evidence to date is contradictory. What can be affirmed is that, in the patients' own generation, the cardinal factor is not a downward occupational drift, but their original position in the social order.

Ignorance, poverty, rootlessness, lack of tradition, and absence of pride in skilled work are all implicated in the causation of mental illness, for they leave the individual defenceless against its onset. The securing of an accepted role in the community is essential for the mental health of every person, and it has been said that the failure of our society to provide adequately for such roles is the most important single factor in mental disorder (Burgess, 1956). If mental disorder is produced by social stress acting upon those who are predisposed, it is liable to be maintained and aggravated by the same cause. It is impossible adequately to convey the nature of this stress by a single phrase and the attempt to do so leads to over-simplification. Two related factors have however been identified: low occupational prestige and social isolation. There is still a large section of the community to which modern concepts of mental illness and mental health have not penetrated. The outcome of mental disorder may depend upon early diagnosis and treatment, and for this reason the patient's path to psychiatric treatment should be made as short and painless as possible. Among the lower strata of our society, mental illness is still too often regarded with dread or with ridicule, and the psychiatrist with suspicion. More educational measures are needed to spread enlightened concepts of mental health to every part of society. But these 
will not be successful unless the Mental Health Service provided can justify the confidence for which we ask. The inculcation of a new attitude to psychiatric treatment depends upon the relationship established between the psychiatric service and the patients who come under its care (W.H.O., 1959).

Much can be done to combat the harmful effect upon the patient of low occupational prestige. Rehabilitation in the true sense begins when the patient begins treatment and a great deal can be achieved in the hospital environment, once the acute stage of illness has been passed, to inculcate good social attitudes and regular habits of work. The development of occupational therapy, and in recent years of "industrial therapy" for the more chronic type of patient (Carstairs, O'Connor, and Rawnsley, 1956; Collins, Manners, Flynn, and Morgan, 1959), provides opportunity for preparing the schizophrenic patient for his return to the community. Moreover, patients who are sufficiently recovered, and who are considered to be in need of more active rehabilitation, may be referred to a Ministry of Labour Industrial Rehabilitation Unit, and thence possibly to a Government Training Centre; and there is evidence that such a rehabilitation course may have a beneficial effect upon the patient's clinical condition (Wing and Giddens, 1959). The provision of more training facilities, and of sheltered workshops, as well as a better liaison both with the Ministry of Labour and with private industry, is needed to ensure the return of the schizophrenic to useful employment. Once the schizophrenic patient, of whatever social status, can return to a community which has not forgotten him and offers him a socially useful role, his prognosis will be greatly improved.

Psychiatrists can do a great deal to bring this about, but in the long run the attitude of society as a whole is involved. The economic structure must continue to rely to some extent upon semi-skilled and unskilled labour, but social prestige should not be reserved for those of high ability and technical skill; all serve the community, and the less skilled worker is entitled to an accepted social role (Glass, 1954).

The present study is a small one. It needs reduplication and extension, on a larger scale and in other parts of Great Britain. If its findings are substantially confirmed, it may make some contribution to our knowledge of the ecology of schizophrenia, and may help to provide a theoretical basis for future community programmes of treatment and prophylaxis.

\section{SUMMARY}

(1) The relationship between social class and outcome of schizophrenic illness was studied in 192 male patients discharged from their first stay in a mental hospital, over a 5-year period.

(2) Several measures of outcome were found to be related to social class: these included success or failure of rehabilitation, total time spent in a mental hospital in subsequent years, and social and economic status at follow-up.

(3) The various hypotheses for the class-distribution of schizophrenia are discussed in the light of these results.

(4) The implications for a programme of social psychiatry are discussed.

I wish to thank Dr. R. E. Hemphill, Medical Superintendent, for permission to carry out this work; Mrs. R. Somers for invaluable assistance with the case work; Mr. R. G. Greenslade, Records Officer, for help wtih the case records; Mrs. V. York for assistance with the manuscripts.

\section{REFERENCES}

Adler, L. McK. (1956). In "Mental Health and Mental Disorder", ed. A. M. Rose and others, p. 501. Routledge and Kegan Paul, London.

Brown, G. W., Carstairs, G. M., and Topping, G. (1958). Lancet, 2, 685.

Burgess, E. W. (1956). In "Mental Health and Mental Disorder", ed. A. M. Rose and others, p. 3. Routledge and Kegan Paul, London.

Carstairs, G. M., O'Connor, N., and Rawnsley, K. (1956). Brit. J. prev. soc. Med., 10, 136.

Collins, S. D., Manners, F., Fynn, S. J., and Morgan, R. (1959). Lancet, 2, 609.

Glass, D. V. (1954). "Social Morbidity in Britain". Routledge and Kegan Paul, London.

General Register Office (1951). "Classification of Occupations, 1950". H.M.S.O., London.

Harris, A., Linker, I., Norris, V., and Shepherd, M. (1956). Brit.J.prev. soc. Med., 10, 107.

Hollingshead, A. B., and Redlich, F. C. (1958). "Social Class and Mental Illness". Wiley, New York.

Mettler, F. A., Crandell, A., Wittenborn, J. R., Litten, K., Feiring, E. H., and Carpenter, M. B. (1954). Psychiat. Quart., 28, 549.

Wing, J. K., and Giddens, R. G. T. (1959). Lancet, 2, 505.

World Health Organization (1949). "Manual of the International Statistical Classification of Diseases, Injuries, and Causes of Death". W.H.O., Geneva.

(1959). "Social Psychiatry and Community Attitudes: Seventh Report of the Expert Committee on Mental Health", Wld Hlth Org. techn. Rep. Ser., No. 177. W.H.O., Geneva. 